\title{
Coordinated Control Strategies for Offshore Wind Farm Integration via VSC-HVDC for System Frequency Support
}

Li, Yujun; Xu, Zhao; Østergaard, Jacob; Hill, David J.

Published in:

IEEE Transactions on Energy Conversion

Link to article, DOI:

10.1109/TEC.2017.2663664

Publication date:

2017

Document Version

Peer reviewed version

Link back to DTU Orbit

Citation (APA):

Li, Y., Xu, Z., Ø̈stergaard, J., \& Hill, D. J. (2017). Coordinated Control Strategies for Offshore Wind Farm Integration via VSC-HVDC for System Frequency Support. IEEE Transactions on Energy Conversion, 32(3), 843-856. https://doi.org/10.1109/TEC.2017.2663664

\section{General rights}

Copyright and moral rights for the publications made accessible in the public portal are retained by the authors and/or other copyright owners and it is a condition of accessing publications that users recognise and abide by the legal requirements associated with these rights.

- Users may download and print one copy of any publication from the public portal for the purpose of private study or research.

- You may not further distribute the material or use it for any profit-making activity or commercial gain

- You may freely distribute the URL identifying the publication in the public portal 


\title{
Coordinated Control Strategies for Offshore Wind Farm Integration via VSC-HVDC for System Frequency Support
}

\author{
Yujun Li, Student Member, IEEE, Zhao Xu, Senior Member, IEEE, Jacob Østergaard, Senior Member, IEEE, \\ David J. Hill, life Fellow, IEEE
}

\begin{abstract}
Coordinated control strategies to provide system inertia support for main grid from offshore wind farm that is integrated through HVDC transmission is the subject matter of this paper. The strategy that seeks to provide inertia support to the main grid through simultaneous utilization of HVDC capacitors energy, and wind turbines (WTs) inertia without installing the remote communication of two HVDC terminals is introduced in details. Consequently, a novel strategy is proposed to improve system inertia through sequentially exerting DC capacitors energy and then WTs inertia via a cascading control scheme. Both strategies can effectively provide inertia support, while the second one minimizes the control impacts on harvesting wind energy with the aid of communication between onshore and offshore $\mathrm{AC}$ grids. Case studies of a wind farm connecting with a HVDC system considering sudden load variations have been successfully conducted to compare and demonstrate the effectiveness of the control strategies in DIgSILENT/ PowerFactory.
\end{abstract}

Index Terms - offshore wind farm, VSC-HVDC, frequency regulation, cascading control, inertia support

\section{INTRODUCTION}

$\mathrm{I}_{\mathrm{b}}^{\mathrm{N}}$ NTENSIVE focuses have been recently drawn on renewable energy development to combat climate change. With the target of $20 \%$ total power from renewable by 2020 set by European Union [1], projects like "Super Grid" in Europe and other similar ones are envisaged and proposed. The impact on $\mathrm{AC}$ system dynamic stability is increasingly significant and profound when the penetration of renewable energy in power system becomes sufficiently high.

Unlike the conventional power plants, most renewable generators are interfaced with the grid through power electronic converters. The main function of these converters is to realize the maximum power point tracking (MPPT) [2] for harvesting solar or wind energy and control the power transmission to the grid side with, however, zero or little inertia. This means that, given the same disturbance, the rate of change of system frequency (ROCOF) during first few seconds will grow significantly along with further deployment of the renewable energy in the future.

\footnotetext{
This work was partially supported by Hong Kong RGC Theme Based Research Scheme Grants No. T23-407/13N and T23-701/14N.

$\mathrm{Y}$. Li is with the School of Automation, the Guangdong University of Technology, Guangzhou, China. He is also with the Department of Electrical Engineering, The Hong Kong Polytechnic University, Hong Kong (email: yujunlizju@gmail.com).

Z. Xu are with the Department of Electrical Engineering, The Hong Kong Polytechnic University, Hong Kong (email: eezhaoxu@polyu.edu.hk).

J. Østergaard is with Centre for Electric Power and Energy (CEE), Technica University of Denmark, 2800 Kgs. Lyngby, Denmark (e-mail: joe@elektro.dtu.dk).

D. Hill is with Department of Electrical and Electronic Engineering, The University of Hong Kong, Pokfulam Road, Hong Kong (dhill@eee.hku.hk)
}

\section{A. Related works}

The prominent advantage of power electronics interfaced wind or solar system is that they can regulate the active or reactive power transmitted to the power grid independently and rapidly. This property can be exploited to render system inertia support recently. [3] firstly proposes WT virtual inertia control method, which imitates the inertia of synchronous generator (SG) to improve system dynamic behavior. The authors further develop the detailed analysis of droop-control DFIG units in microgrids [4]. Recently, [5] proposes a novel method by shifting the turbine operating points from MPPT curve to provide turbine virtual inertia.

Nowadays, more and more large scale, far offshore wind farms are getting integrated into system through HVDC transmission due to the limitation of traditional AC transmission [6, 7]. Wind farm integration by conventional line commutated converter (LCC) HVDC system and full-bridge diode rectifier based HVDC is studied in [8] and [9], respectively. However, little voltage or reactive support can be provided to the main grid by wind farm due to the uncontrollability of such HVDC systems. Nevertheless, HVDC based on voltage source converter (VSC) utilizing full-controllable components such as IGBT or GTO can enable AC voltage support to the connected AC system by wind farm.

With respect to the inertia support for power grid from offshore wind farm integration through VSC transmission, [10] proposes a control strategy utilizing the energy stored by HVDC capacitors to provide system inertia support for onshore AC grid. However, the provided support is very limited, since large deviation of HVDC voltage is not permitted, which limits the stored energy by HVDC capacitors. [11] and [12] propose to utilize HVDC capacitor energy and WTs inertia simultaneously to provide system inertia support to the AC main grid. [13] and [14] proposes a coordinated control of DC capacitor energy and WTs inertia for system inertia support. Another coordinated control of HVDC capacitor and wind farm seeking to provide frequency regulation service for both under-frequency and over-frequency events are fully designed in [15]. Actually, all those studies concern on establishing artificial coupling methods between offshore and onshore networks using the VSC-HVDC link. This coordinated coupling strategy has one significant merit of no utilization of remote communication between two terminals of HVDC to provide system inertia support during onshore AC grid frequency excursion. Moreover, it is widely utilized in the improving fault ride through capability for wind farms connected through HVDC transmission $[16,17]$ and frequency support for wind farms connected through Multi-terminal DC network [18]. 


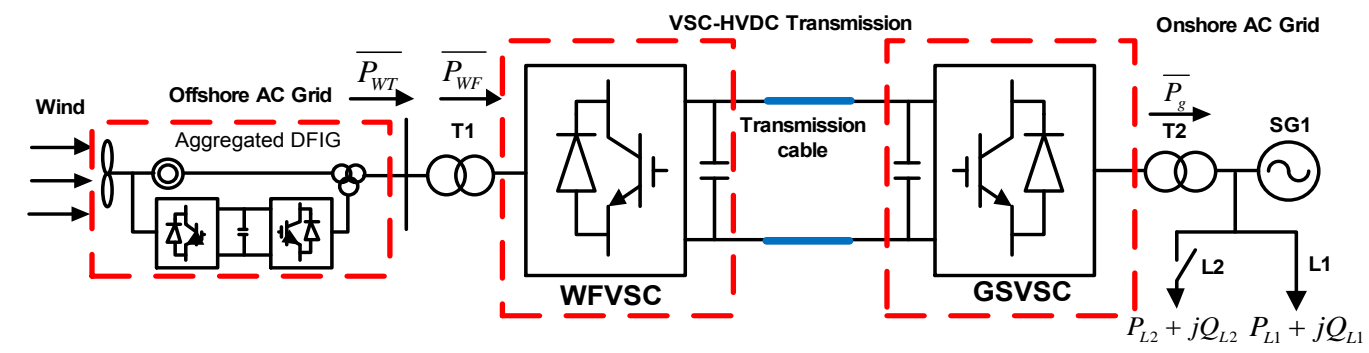

Fig. 1. System outline of a point-to-point HVDC system for wind farm connection

\section{B. Main contribution}

One drawback of the coordinated coupling strategy in [11-15] is that it requires wind farm constantly deviating from the MPPT status whenever frequency disturbances occur, which may not be a cost-effective strategy for commercial wind farms. Considering inertia support from the offshore wind farm integrated via VSC-HVDC transmission, this paper further investigates the control strategies in [13] and [14] in order to fully utilize the system's potentials to regulate system frequency. Specifically, a cascading control strategy is proposed to minimize the control impacts on wind energy harvesting while providing system frequency support by firstly exerting HVDC capacitor and then WT inertia with the aid of communication between the onshore and offshore grids. An expression of synthetic inertia is calculated, which is used to quantify the contribution of offshore wind farm connected HVDC system to the total inertia of the onshore main grid. In order to illustrate and validate the proposed cascading control, two different virtual inertia control strategies for improving system inertia level involving simultaneous control in [13] and the proposed cascading control respectively are fully developed and compared. Case studies considering various disturbance scenarios have demonstrated that the cascading control can not only effectively coordinate wind farms and HVDC to work together for system inertia support but also minimize the control impacts on wind farm energy harvesting. Furthermore, the potential impact of time delay involved in remote communication of two HVDC converters on the performance of the proposed cascading control is studied as well.

\section{SYSTEM TOPOLOGY AND CONVECTIONAL CONTROL SCHEME}

\section{A. System configuration}

In order to illustrate the proposed control strategy, a typical point-to-point HVDC system connecting with a wind farm (WF) is studied in this paper without loss of generalities. Fig.1 shows the system outline, where one WF is connected to AC main grid via two HVDC converters including the wind farm VSC (WFVSC) and grid side VSC (GSVSC).

In this paper, the offshore WF is simulated using an aggregated model [7-9] with the single rating of $300 \mathrm{MW}$. The DFIG model and the control strategy can be referred to [19] and [20]. The power ratings of the GSVSC and WFVSC are set as $300 \mathrm{MW}$ in case studies later on. The onshore AC grid contains two local loads (L1 \& L2) and one 300MW synchronous generator (SG1) built by a seventh-order model [22] that represents the power grid. Notably, the same power rating set for the power system and WF aims to better illustrate the performance of two control strategies. L1 consists of a fixed load $P_{L I}+j Q_{L l}$ as $400 \mathrm{MW}+40 \mathrm{Mvar}$, and the other switchable load

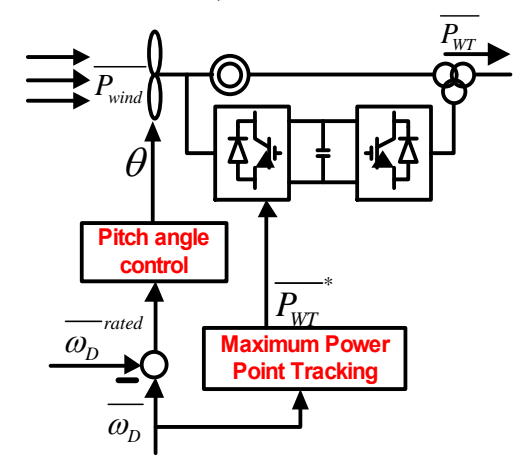

Fig. 2. DFIG power control scheme

$P_{L 2}+j Q_{L 2}$ as $40 \mathrm{MW}+10 \mathrm{Mvar}$. More parameters of the case system are shown in Appendix Tables A1 A2.

\section{B. DFIG active power control}

The active power generated by the aggregated DFIG is controlled through the Maximum Power Point Tracking (MPPT) algorithm and the pitch angle control as shown in Fig.2. The MPPT algorithm is implemented to calculate and set the optimal active power reference according to the current rotor speed in per unit form $\left(\overline{\omega_{D}}\right)$. In the following, control signals are in per unit form. Subsequently, the rotor speed dynamics is governed by the rotor motion equation in (1),

$$
2 H_{D} \cdot \overline{\omega_{D}} \cdot \frac{d \overline{\omega_{D}}}{d t}=\overline{P_{\text {wind }}}-{\overline{P_{W T}}}^{*}
$$

where, $H_{D}$ is the inertia constant of DFIG, $\overline{P_{\text {wind }}}$ and $\overline{P_{W T}}{ }^{*}$ are the captured power from the WT and the reference active power from the MPPT, respectively. Due to the fast response of power electronic devices, active power from WT can be regarded as same as its power reference, that is $\overline{P_{W T}}={\overline{P_{W T}}}^{*}$. Pitch angle control is activated to constrain the rotor speed within its limit by increasing the pitch angle once over-speed of WT rotor is detected.

The mathematical expression of $P_{\text {wind }}$ is as follows [24]:

$$
\begin{gathered}
P_{\text {wind }}=\frac{\rho}{2} \pi R^{2} v_{w}{ }^{3} C_{p}(\lambda, \theta) \\
\lambda=\frac{\omega_{t} \cdot R}{v_{w}}=\frac{k \cdot \omega_{D} \cdot R}{v_{w}}
\end{gathered}
$$

where $\rho$ is the air density, $R$ is the rotor blade radius, $v_{w}$ is the wind speed, $C_{p}$ is the power coefficient, $\lambda$ is the tip speed ratio, $k$ is the gear ratio of gearbox, $\omega_{t}$ is the wind turbine rotational 


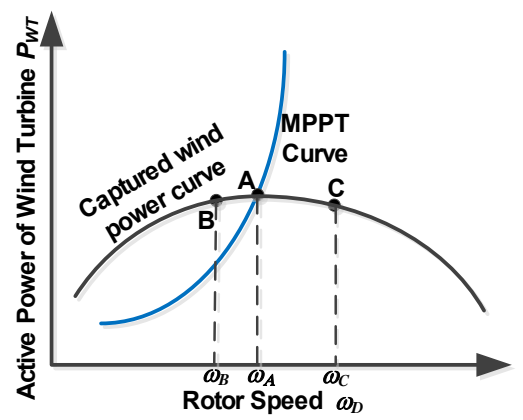

Fig. 3. Wind turbine operation characteristic

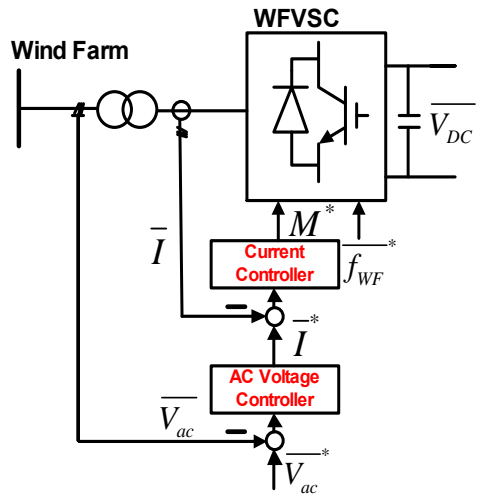

Fig. 4. Control scheme of WFVSC

speed and $\theta$ is the pitch angle. Normally, the pitch angle is controlled to zero when $P_{\text {wind }}$ is below the rated power. Thus, $C_{p}$ is the function of $\lambda$ only and reaches the maximum $C_{p m a x}$ at certain $\lambda$. At this point, it obtains the optimal $\omega_{D}$ for a given $v_{w}$ from (3), as shown in point A in Fig. 3. Any operation rotor speed deviation from optimal $\omega_{D}$ results in the reduction of the captured wind power, as shown in point B and C in Fig. 3.

\section{Wind Farm VSC (WFVSC)}

For the case system, the DFIG rotor speed is effectively decoupled from the system speed due to the separation by the electronic converters of DFIGs and HVDC. Therefore, there is little change of active power production of wind farm in response to any system frequency variations. Thus, offshore AC grid frequency can be controlled at a constant value $\overline{f_{W F}} *$ in Fig. 4. Wind farm AC voltage is controlled by the outer voltage control loop and inner current control loop of WFVSC, which can guarantee the fast tracking of the reference voltage and current. Consequently, the WFVSC can be regulated as an ideal voltage source as shown in Fig.4.

\section{Grid Side VSC (GSVSC)}

As shown in Fig.5, a classical controller is implemented for the GSVSC to ensure power transmission from WFVSC to the grid. The entire control scheme adopts the grid voltage reference frame where the $d$-axis is chosen collinear to the grid voltage $[23,25]$. The phase-lock loop (PLL) is utilized to calculate the rotating angle $\theta_{P L L}$ for the $d q$ transformation. The VSC controller is made up of two cascaded control loops. The outer power loop controls the DC voltage $V_{D C}$ and the reactive power $Q$, which are associated with the $d$-axis current $i_{d}$ and the $q$-axis current $i_{q}$, respectively. The reference voltage $V_{D C}$ in conventional control is set as a constant that guarantees the

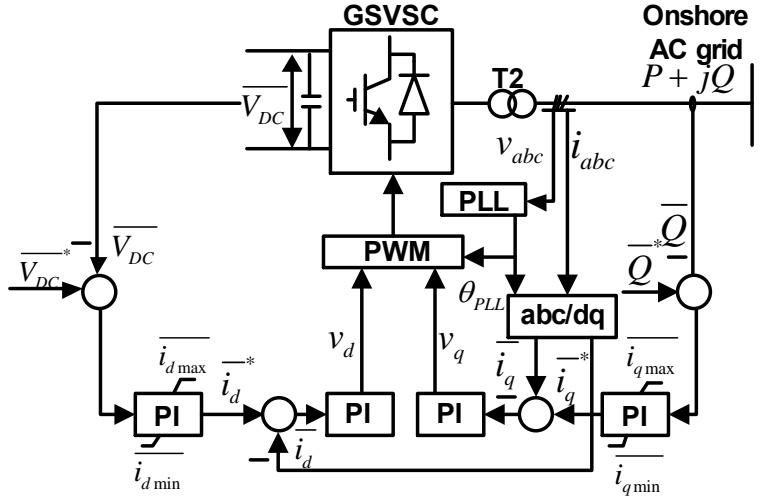

Fig. 5. Conventional Control scheme of GSVSC

power balancing between the onshore and offshore AC grids. Normally, the reactive power output is set as zero to make sure the unity power factor of the offshore AC grid. $v_{d}$ and $v_{q}$, which are obtained from the inner current control loop, are used to generate the desired AC voltage. Limitations on $i_{d}$ and $i_{q}$ are required to prevent the over-current of the converters.

\section{StRATEgy I: SimultaneOUS CONTROL}

In order to obtain the inertial response from the HVDCconnected wind farms, the first strategy seeks to utilize HVDC link capacitors energy and WT inertia simultaneously, which is implemented based on exerting inertia support from HVDC link capacitors and the support of the wind farm simultaneously. Further, a communication-free coupling scheme between onshore and offshore AC grids for transmitting main grid frequency signal to offshore wind farm is properly designed.

\section{A. Inertia support from HVDC link capacitors}

The voltage of HVDC link capacitors reflects the power balance of the power injected into WFVSC $\overline{P_{W F}}$ and the power transmitted to the onshore AC grid, $P_{g}$ if ignoring the power losses in HVDC transmission cables. The dynamics of the HVDC voltage $\overline{V_{D C}}$ in per unit form can be written as follows:

$$
\begin{gathered}
C \cdot \overline{V_{D C}} \cdot \frac{d \overline{V_{D C}}}{d t}=\overline{P_{W F}}-\overline{P_{g}} \\
C=\frac{C_{D C} \cdot V_{D C n}{ }^{2}}{S_{B}}
\end{gathered}
$$

where $S_{B}$ is the base value of the system. $C_{D C}, C$ are the total capacitance and the equivalent capacitance in p.u., respectively. $V_{D C n}$ is the nominal value of the HVDC link voltage. In the following deduction, all the variables are in the per unit form.

It is well understood that any imbalance between the load and generation in the power system will lead to the alternation of the system frequency. A synchronous generator (SG) intrinsically uses its mechanical inertia to smooth the frequency deviation. The process can be written as follows:

$$
2 H \cdot \bar{f} \cdot \frac{d \bar{f}}{d t}=\overline{\Delta P}
$$

where $H$ is SG inertia constant, and $\bar{f}$ is the system frequency. $\overline{\Delta P}$ is the deviation between the mechanical and the electrical power of the SG. It is noted that the value of $H$ determines the ROCOF. Given the same time frame, the higher $H$ is, the smaller frequency variation will result. 


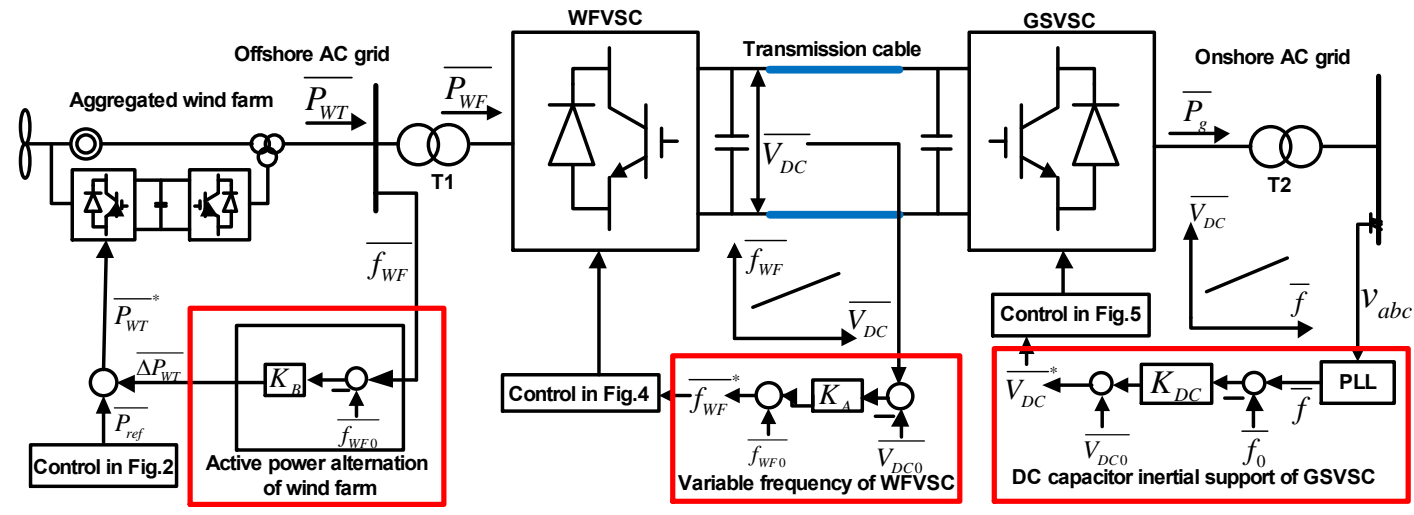

Fig. 6. Control scheme of the simultaneous control

In order to emulate the inertia constant in (6), $\overline{P_{W F}}$ and $\overline{P_{g}}$ in (4) can be roughly regarded as the mechanical and electrical power inputs to a SG, respectively. The DC voltage, to some extent, is analogous to the system frequency, thus

$$
C \cdot \overline{V_{D C}} \cdot \frac{d \overline{V_{D C}}}{d t}=2 H_{D C} \cdot \bar{f} \cdot \frac{d \bar{f}}{d t}
$$

where $H_{D C}$ is the equivalent virtual inertia constant provided by the HVDC. Integrating two sides of (7) over time,

$$
\begin{gathered}
\int_{\bar{V}_{D C 0}}^{\overline{V_{D C}}} C \cdot \overline{V_{D C}} \cdot \frac{d \overline{V_{D C}}}{d t}=\int_{\bar{f}_{0}}^{\bar{f}} 2 H_{D C} \cdot \bar{f} \cdot \frac{d \bar{f}}{d t} \\
\frac{C \cdot\left({\overline{V_{D C}}}^{2}-{\overline{V_{D C 0}}}^{2}\right)}{2}=H_{D C} \cdot\left(\bar{f}^{2}-{\overline{f_{0}}}^{2}\right)
\end{gathered}
$$

where $\overline{V_{D C O}}$ and $\overline{f_{0}}$ are the nominal values of the HVDC voltage and the system frequency, respectively. Normally, they are set as 1 p.u. In practice, the HVDC voltage will vary within a small range around the nominal. In this paper, we set the HVDC voltage constraints as \pm 0.1 p.u. The exact value depends on the insulation requirement and PWM pattern. Therefore, (9) can be linearized around its equilibrium point,

$$
C \cdot \overline{V_{D C 0}} \cdot \overline{\Delta V_{D C}}=2 H_{D C} \cdot \overline{\Delta f}
$$

Based on (8), the control process can be derived as follows:

$$
{\overline{V_{D C}}}^{*}=K_{D C} \cdot \overline{\Delta f}+\overline{V_{D C 0}}
$$

where $K_{D C}$ is the control parameter and can be designed properly with respect to some technical requirements e.g. PWM frequency and current rating of VSC etc. The control process above actually forms a HVDC voltage droop control scheme as illustrated in Fig.6. From (10) and (11), the relationship between $H_{D C}$ and $K_{D C}$ can be written as follows:

$$
H_{D C}=\frac{K_{D C} \cdot C \cdot \overline{V_{D C}}}{2}
$$

\section{B. Communication-free coupling scheme}

The wind farm needs to perceive the variation of the onshore AC grid frequency before it can provide corresponding inertia support. This can be achieved by transmitting the measured frequency signal through dedicated communication channel, which may not be an ideal choice from the cost and reliability perspectives. Alternatively, the coupling of the onshore main grid and offshore wind farm without remote communication can be established through using HVDC link voltage. Ignoring the power loss along HVDC cables, the HVDC voltage at the WFVSC and the GSVSC are regarded the same. When there is main grid frequency deviation, it can be firstly converted into the variation of the HVDC voltage through HVDC voltage droop control discussed in the preceding section, and subsequently the offshore AC grid frequency can follow such change through a proper droop design according to,

$$
\overline{\Delta f_{W F}}=K_{A} \overline{\Delta V_{D C}}
$$

where $\overline{\Delta f_{W F}}$ is the deviation of the frequency of the offshore AC grids, and $K_{A}$ is the control parameter, which stands for the proportion of the offshore $\mathrm{AC}$ grid frequency deviation $\overline{\Delta f_{W F}}$ to the DC voltage deviation $\overline{\Delta V_{D C}}$ at the WFVSC. Combined (11) and (13), the coupling of onshore and offshore AC grid frequency is established in (14),

$$
\overline{\Delta f_{W F}}=K_{A} K_{D C} \overline{\Delta f}
$$

\section{Wind farm inertia support}

In order to implement the wind farm virtual inertia, the wind farm output power $\overline{P_{W F}}$ should alter in response to the system frequency as a conventional SG does. Similar to (6), the dynamic equation of wind farm can be described as (15):

$$
2 H_{W F} \cdot \bar{f} \cdot \frac{d \bar{f}}{d t}=\overline{P_{W F 0}}-\overline{P_{W F}}
$$

where $\overline{P_{W F 0}}$ is the initial active power of wind farm, which is analogous to the mechanical power of a SG. $\overline{P_{W F}}$ is mimicking the electrical power of the SG. $H_{W F}$ is the virtual inertia provided by wind farm.

A typical and direct way to make the DFIG based WT responsive to the offshore AC grid frequency (coupling to onshore AC grid frequency as (14) illustrates) is by adding the power deviation $\overline{\Delta P_{W T}}$ that is proportional to the variation of offshore AC grid frequency $\overline{\Delta f_{W F}}$ to the original power reference of WT, $\overline{P_{r e f}}$. The proportional coefficient is denoted as $K_{B}$ in the following analysis. Therefore, the WT inertia control adopted in this paper is actually a droop control. Combining (11) and (12), yielding,

$$
\begin{aligned}
{\overline{P_{W T}}}^{*} & =\overline{P_{r e f}}+\overline{\Delta P_{W T}}=\overline{P_{r e f}}+K_{B} \overline{\Delta f_{W F}} \\
& =\overline{P_{r e f}}+K_{B} K_{A} \overline{\Delta V_{D C}}
\end{aligned}
$$

In order to realize (16), one possible way is to utilize the reserved energy by pitching [15] to compensate the power gap between output active power of WT and the input wind energy. However, WT should deviate from MPPT operating statuses and the response speed is rather slow due to the mechanical 
regulation of pitch angle. Instead, WT inertia $[3,4]$ adopted in this paper can absorb or release the imbalanced power $\Delta P_{W T}$ for short durations, which provides faster response and is more energy efficient compared with the control strategy in [15].

The active power of the WT can be controlled to a new value by its rotor side converter quickly. If the power losses in the wind power collecting network are neglected, the active power from the aggregated DFIG equals to the power output of the

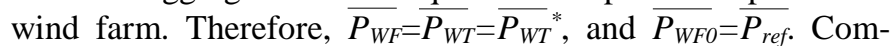
bining (15) and (16),

$$
2 H_{W F} \frac{d \bar{f}}{d t}=\overline{P_{W T}}-\overline{P_{r e f}}=-K_{A} K_{B} K_{D C} \overline{\Delta f}
$$

Integrating two sides,

$$
H_{W F}=-\frac{\int_{t_{0}}^{t} K_{A} K_{B} K_{D C} \overline{\Delta f} d t}{2 \overline{\Delta f}}=-\frac{K_{A} K_{B} K_{D C} \overline{\Delta f_{\text {avg }}} \Delta t}{2 \overline{\Delta f}}
$$

where $\overline{\Delta f_{\text {avg }}}$ is the average frequency deviation from $t_{0}$ to $t$. In order to obtain a positive $H_{W F}, K_{W F}$ should be negative.

In terms of the overall system that the offshore wind farm is integrated through HVDC transmission, the HVDC capacitors and the WT inertia together provide the system inertia support, then the overall virtual inertia constant $H_{s}$ provided through the simultaneous control is written as follow,

$$
H_{s}=H_{D C}+H_{W F}
$$

Fig.6. shows the control scheme of the control strategy I. Taking the main grid frequency drop as an example to address the whole process, the GSVSC firstly lowers its DC voltage reference in response to the decreasing system frequency; correspondingly the HVDC capacitor releases its energy for the system inertia support. Meanwhile, the lowered HVDC voltage will lead to a lowered offshore AC grid frequency. Consequently, the WT will increase its active power output followed by the decreasing offshore AC grid frequency. Through a series action of the above controllers, the main grid frequency variation and ROCOF can be reduced, and the overall system stability can be enhanced.

\section{StRATEgy II: Proposed CASCADING CONTROL}

In the strategy I, wind farm and HVDC link capacitors simultaneously provide inertia support for the main grids once disturbances occur. Even though this strategy can fully utilize the system self-inertia to increase the system stability without remote communication between two HVDC converter stations, it may require wind farm constantly deviating from the optimal reference points whenever frequency disturbances occur. However, using WT inertia to smooth the system frequency will inevitably lead to the rotor speed deviations from the optimal reference, which is determined by the MPPT algorithm. Put it differently, the strategy I may enable offshore wind farm constantly deviating from its maximum power capture status in response to frequency disturbances, which may not be a costeffective strategy for a commercial wind farm.

To avoid the aforementioned problem, a cascading control strategy that can orderly activate the inertia supports from HVDC capacitors and then WT inertia automatically is proposed. The core of this strategy is that, the energy stored in HVDC capacitors is always firstly utilized for system inertia support, while WT inertia is exerted only if the main grid frequency deviation still exists. In the proposed cascading control, the stored energy in HVDC link is maximally utilized to make sure less wind power is wasted due to the deviations from the maximum power operating points involved into wind farm inertia control while making the optimal use of available resources for system support. In the following, the detailed design of control strategies of GSVSC, WFVSC and wind farm is presented for the cascading control scheme.

\section{A. Cascading control with HVDC capacitors activated only}

Under the cascading control, GSVSC still implements HVDC voltage droop control, which enables the coupling between HVDC voltage and main grid frequency. Notably, the HVDC voltage variation must be in normal operation range. As for WFVSC, the offshore AC grid frequency does not alter when HVDC voltage under its normal range. Therefore, when the system frequency deviation is within a small range, HVDC capacitors will contribute alone for system inertia support, and wind farm inertia control will not be activated, minimizing the impacts to WT MPPT control. Compared to the simultaneous control strategy, the proposed cascading control strategy can ensure better harvest of wind energy while supporting system frequency effectively, which is of great significance in system daily operation where small frequency disturbances prevail.

\section{B. Cascading control with both HVDC capacitors and WT inertial activated}

When HVDC voltage reaches its limitation in events of large system frequency disturbances, HVDC capacitors use up their stored energy. Consequently, WT inertia becomes the last resort for system inertia support. In order to activate wind farm inertia support illustrated in Section III.C, onshore AC grid frequency should be transmitted to the offshore $\mathrm{AC}$ grid through the communication channel. This is because the artificial coupling between onshore and offshore AC grid described in Section III.B does not exist when HVDC voltage beyond normal range. A proper designed dead band for offshore AC grid frequency is essential to orderly cascade HVDC voltage droop control and wind farm inertia support control. In addition, frequent utilization of WT inertia is avoided through the designed dead band described as follows:

$\overline{\Delta f_{W F}}= \begin{cases}K_{A} K_{D C}\left(\bar{f}-\bar{f}^{\prime}-\overline{f_{0}}\right) & \text { when } \overline{V_{D C}}=0.9 \text { or } \overline{V_{D C}}=1.1 \\ 0 & \text { when } 0.9<\overline{V_{D C}}<1.1\end{cases}$

where, $\overline{f^{\prime}}$ is the cut-off frequency, whose value equals to the onshore AC grid frequency when HVDC voltage beyond its limitation, yielding:

$$
\bar{f}^{\prime}= \begin{cases}0.1 / K_{D C} & \text { when } \overline{V_{D C}}=1.1 \\ -0.1 / K_{D C} & \text { when } \overline{V_{D C}}=0.9\end{cases}
$$

Different from the simultaneous control, WT inertia is not activated when HVDC voltage within normal range, and will only be exerted to provide system inertia support once HVDC voltage reaching its limitation according to (20) and (21). Sim ilar to Equation (18), the wind farm virtual inertia is written as follows:

$$
H_{W F}=-\frac{\int_{t_{0}}^{t} K_{B} \overline{\Delta f_{W F}} d t}{2 \overline{\Delta f}}=-\frac{K_{B} \overline{\Delta f_{W F-a v g}} \Delta t}{2 \overline{\Delta f}}
$$




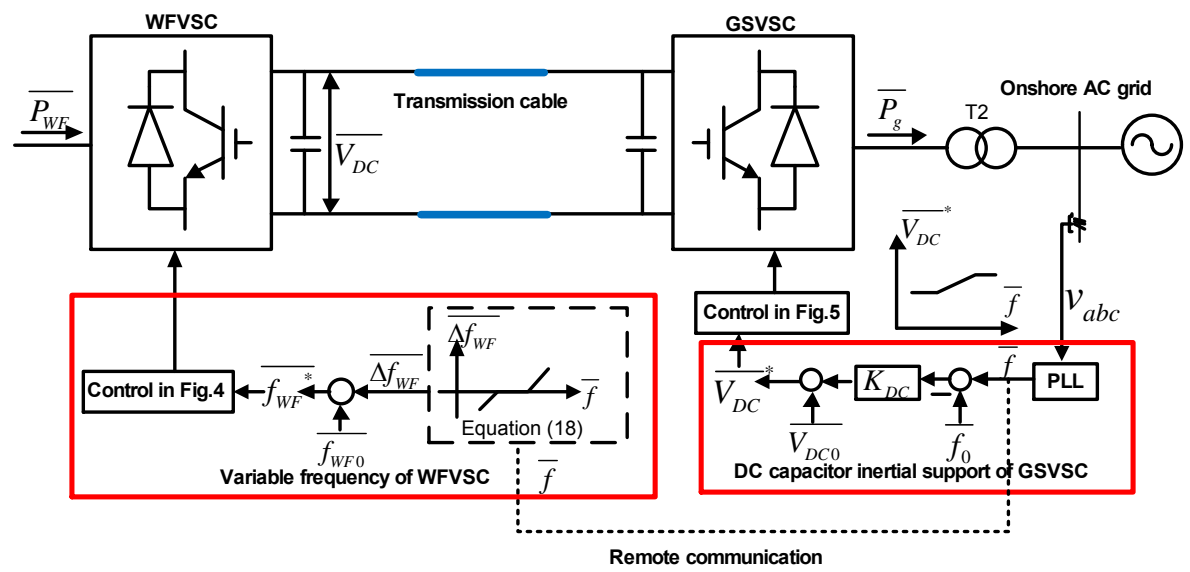

Fig. 7. Control scheme of the cascading control

Fig.7 shows the overall control scheme of the cascading control, then overall virtual inertia constant $H_{s}$ is given below:

$$
H_{s}= \begin{cases}H_{W F} & \text { when } \overline{V_{D C}}=0.9 \text { or } \overline{V_{D C}}=1.1 \\ H_{D C} & \text { when } 0.9<\overline{V_{D C}}<1.1\end{cases}
$$

\section{Selection of control parameters}

In order to fairly compare two control strategies, the control parameters of $K_{D C}$ and $K_{B}$ with cascading control should be tuned properly. $K_{D C}$ of Strategy II is determined based on two following facts:

1. $K_{D C}$ of Strategy II $K_{D C I I}$ should be larger than $K_{D C}$ in Strategy I $K_{D C I}$

Compared (23) with (19), in order to fully utilize the inertia support capability of HVDC capacitors, $K_{D C}$ in Strategy II $K_{D C I I}$ should be larger than $K_{D C}$ in Strategy I $K_{D C I}$. If two $K_{D C}$ in both control schemes are tuned the same, Strategy II may be more energy-saving than Strategy I but cannot provide as much inertia support as Strategy I, which may not take advantage of the Strategy II.

2. $K_{D C}$ in Strategy II $K_{D C I I}$ should be less than the maximum $K_{D C \max }$

WT inertia will be frequently utilized if $K_{D C}$ is set too high, and this will sacrifice the advantage of harvesting as much wind energy as possible by the cascading control. Consequently, the selection of $K_{D C}$ can be based on the specific grid code with respect to the minimum grid frequency deviation for WT inertia control beginning to be activated during system disturbances set by the system operator (the minimum cut-off frequency $\overline{f_{\text {min }}}$ in (21)). Therefore, the $K_{D C \max }=0.1 / \overline{f_{\text {min }}}$.

Therefore, the range of $K_{D C I I}$ is as follows,

$$
K_{D C I} \leq K_{D C I I} \leq K_{D C \max }
$$

The selection criterion of $K_{B}$ of Strategy II is achieving the similar frequency nadir or summit as with Strategy I under the same system disturbances. In the above parameter selection method, the energy saved by two control schemes can be fairly compared while providing similar frequency support via two strategies. Certainly, there are some alternative ways to set the parameters, but this is outside scope of this paper.

\section{Simulation StUdies}

Simulation studies are performed using DISILENT/PowerFactory for the test system shown in Fig.1. The system and control parameters can be referred to the Appendices.

\section{A. Sudden load increase with same control parameters}

Fig.8 shows the sudden load increase event on the onshore AC grid, where the dump load $P_{L 2}+j Q_{L 2}$ is switched on at $t=5 \mathrm{~s}$. Three different situations namely without any additional control, with the control strategies I and II are compared in Fig.8. Control parameters of HVDC voltage droop control and wind farm inertia control $K_{D C}=1.5$ and $K_{B}=-1.5$ are set the same in two control strategies in this case. As shown in Fig.8 (a), it is clearly seen that both control strategies take effect in fast inertia support from wind farm integration via HVDC transmission system. With the simultaneous control, it provides more inertia support and the frequency nadir is higher than that with the cascading control. This is because with the cascading control, inertia support is solely from HVDC capacitor if the HVDC voltage is within its limitation. However, with the simultaneous control, the inertia support is not only from the HVDC capacitor but also from the wind farm. Correspondingly, ROCOF value with simultaneous control is slightly lower than that with cascading control as shown in Fig.8 (b). Therefore, given the same control parameters, the simultaneous control may provide more inertia support than the cascading one when the HVDC voltage is within limitations. Fig.8 (c) shows the mechanical power of SG begins to increase to compensate the load gap. It is obvious that without any control, the mechanical power from SG increases faster than with the Strategy I and II. With the simultaneous control, it increases more softly than with cascading control. Correspondingly, more active power is transmitted to the onshore AC grid from GSVSC than that with the cascading control, as shown in Fig.8 (e). HVDC voltage of both control strategies are within HVDC voltage limitation due to a relatively small $K_{D C}$ selected, as shown in Fig.8 (d). In the simultaneous control, the offshore AC grid frequency is coupled with HVDC voltage and the offshore AC grid frequency drops down as shown in Fig.8 (f). In contrast, since HVDC voltage is still within limitations, the cascading control does not activate wind farm inertia support and the offshore grid frequency does not change at all. Fig.8 (g) shows that the active power from wind farm increases after the system disturbances by the simultaneous control. Correspondingly, it leads to the DFIG rotor speed decreasing to compensate the power gap between its mechanical power and electrical power. Due to the rotor speed deviation from its MPPT speed, the captured wind 

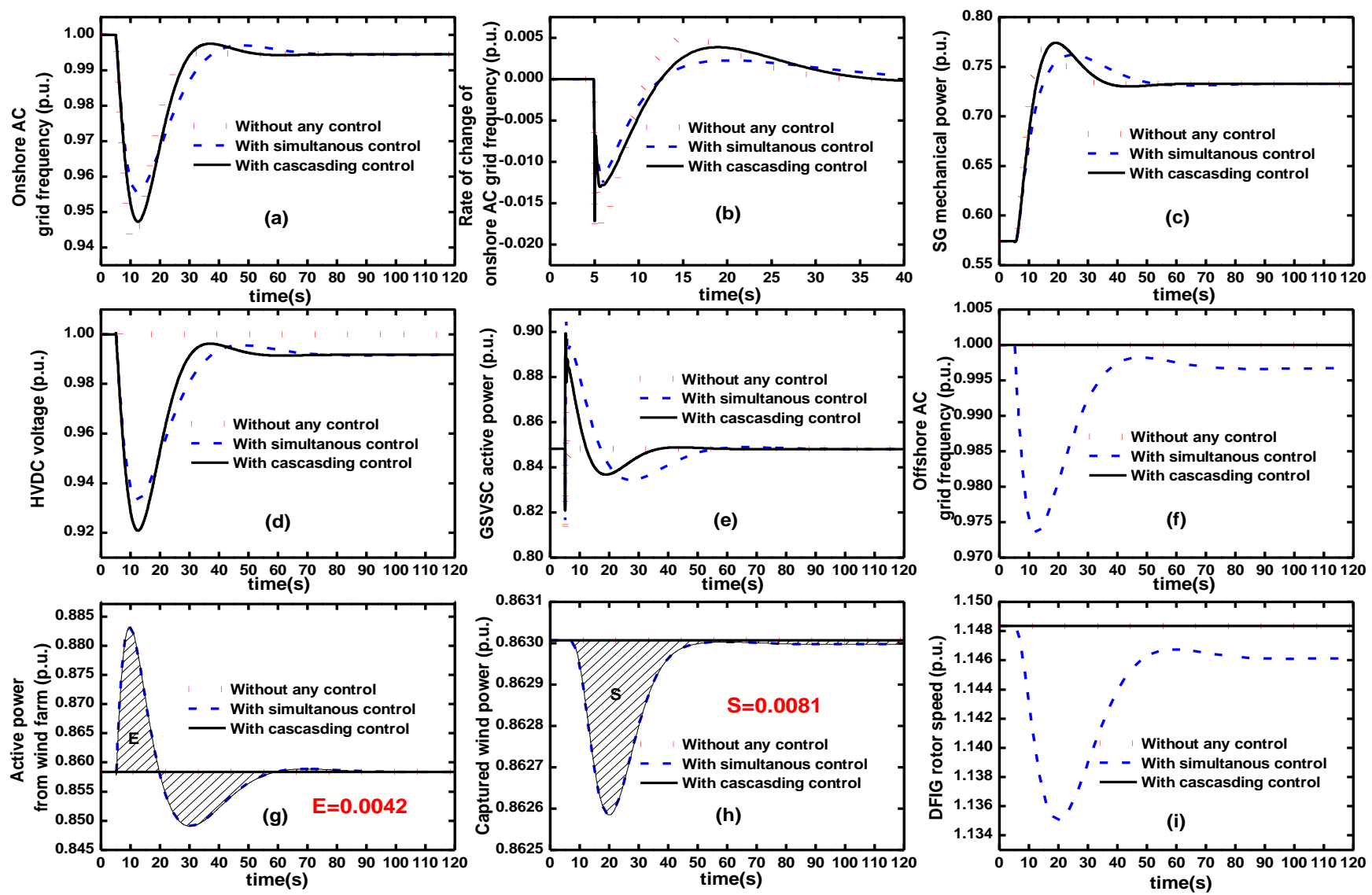

Fig.8 Simulation results for sudden load increase of onshore AC Grid using the same control parameter under HVDC voltage limitation

power is lower from the maximum power point as shown in Fig.8 (h). However, with the cascading control, wind power harvest and rotor speed are not affected in Fig.8 (g) to (i) since wind farm inertia is not activated for system inertia support during the event. Fig. 8 (h) also shows the difference of wind power harvest by the two control strategies is roughly calculated as 0.0081 (shadow area marked in S), which indicates the loss of captured wind energy during system disturbances. However, the shadow area marked in $\mathrm{E}(\mathrm{E} \approx-0.0042)$ as shown in Fig.8 (g) indicates the energy reduction of wind farm during dynamics. The negative value means amount of surplus energy is injected into onshore AC grid. Due to the wind farm inertia control actually as a droop control; there exists a steady error in output power of wind farm and captured wind power as shown in Fig.8 (g) and (h). As a result, it is not unreasonable of negative E since amount of DFIG kinetic energy is released after recovery from the system disturbances, as shown in Fig. 8 (i). Thus, the cascading control can be more energy efficient while providing similar control functions.

\section{B. Sudden load increase with different control parameters}

Fig.9 shows the same sudden load increase event on the main grid. Different control parameters are adopted. HVDC voltage droop control parameter $K_{D C}$ is set as 1.5 and 3 for the strategies I and II respectively. The selection of $K_{D C}$ in Strategy II is based on the minimum cut-off frequency $\bar{f}_{\min }$. In this paper, $\overline{f_{\min }}$ is selected as 0.02 p.u. Correspondingly, $K_{D C \max }=5$. In order to better illustrate the difference between two control schemes, a larger $K_{D C}$ for strategy II $\left(K_{D C I I}=3\right)$ is selected. In order to achieve similar frequency nadirs, $K_{B}$ of the two strate- gies are set as -1.5 and -10 , respectively. Fig.9 (a) and (b) show that, with the simultaneous control, the ROCOF in the inception of the event is slightly larger than that of the cascading control. This is not unreasonable since strategy II adopts a larger HVDC voltage droop control parameter, and therefore GSVSC provides more inertia support. Correspondingly, the mechanical power received by SG under system disturbance is less with the cascading control in the inception of the event as shown in Fig.9 (c). As shown in Fig.9 (d), due to the larger $K_{D C}$, the cascading control actually enables HVDC voltage to reach its limitations faster, and once this occur, the cascading control will activate the wind farm inertia support. Because of different control strategies, offshore AC grid frequency exhibits different profiles under the three situations in Fig.9 (f). Fig.9 (g) shows clearly the power output from wind farm increases along with the decrease of offshore $\mathrm{AC}$ grid frequency for the two control strategies. The increased output power is achieved by WT rotor speed reduction to release its kinetic energy as shown in Fig.9 (i). It is noted in Fig.9 (h) that the cascading control causes less loss of wind energy production compared to the simultaneous control during the disturbance. The actual wind energy losses are 0.0081 per unit (marked as S1) and 0.0025 (marked as S2) for the simultaneous control and the cascading control respectively, which validates the advantage of the latter. In addition, the simultaneous control appears to cause a significant and constant deviation from the optimal rotor speed in Fig. 9 (j), which is obviously less energy efficient. However, due to the rotor speed deviation from the optimal speed after disturbances, amount of rotor kinetic energy is released to the onshore AC grid, which results in the 

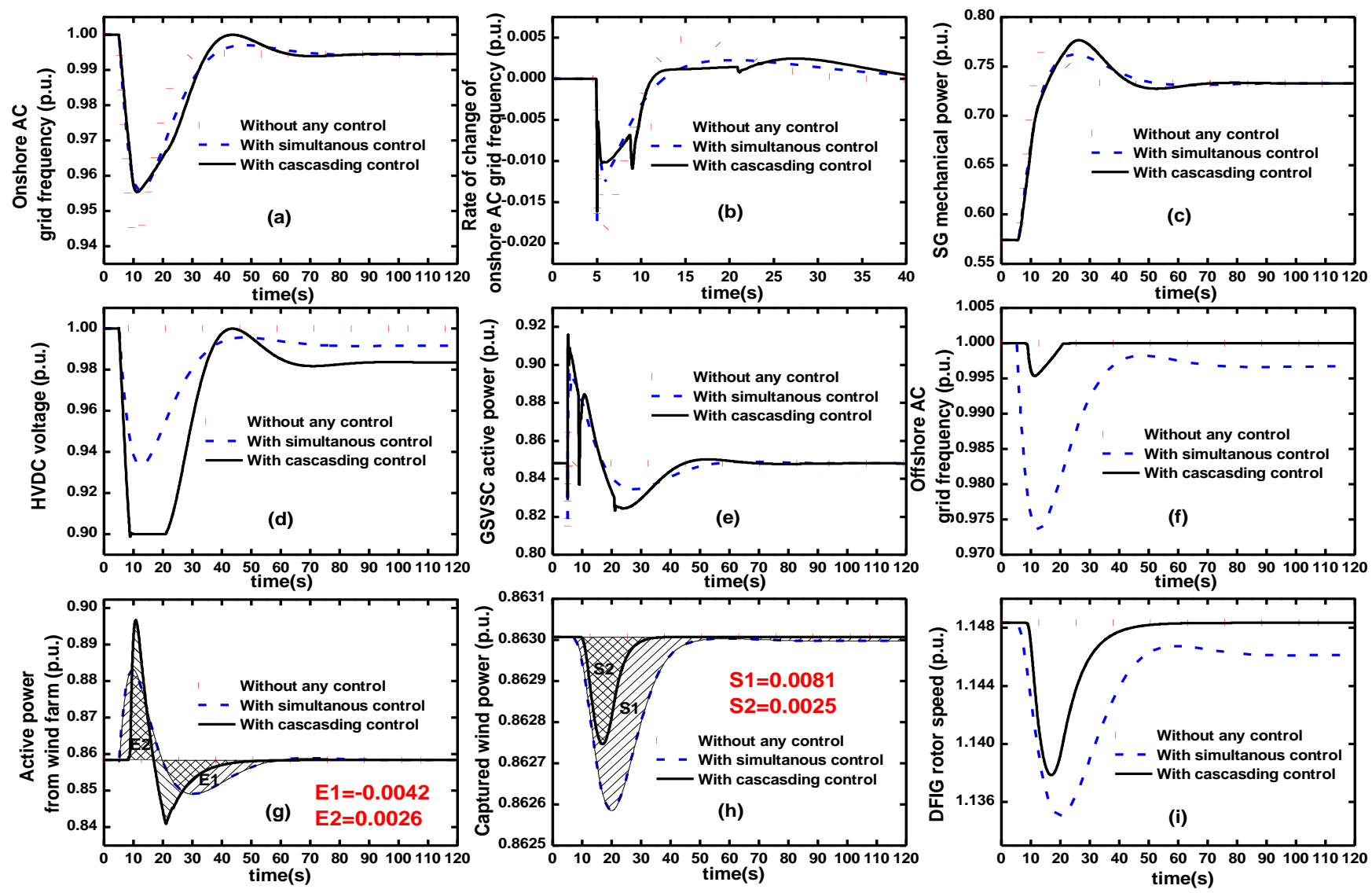

Fig.9 Simulation results for sudden load increase of onshore AC Grid with different control parameter

energy reduction of wind farm -0.0042 per unit (marked as E1) different from the loss of captured wind energy 0.0081 per unit (marked as S1) with simultaneous control. However, in the cascading control, energy reduction of wind farm (marked as E2) is nearly the same as loss of captured wind energy S2.

\section{Sudden load decrease with different control parameters}

Fig.10 shows a sudden load decrease event on the onshore AC grid, where the dump load is suddenly switched out at $t=5 \mathrm{~s}$. It is clearly seen that, with two virtual inertia control schemes, frequency peaks during the disturbance are lower than the case without any additional control. In order to compare the impact on energy harvesting, the control parameters of the two control strategies are chosen the same as in Case B. Because of larger voltage droop control parameter $K_{D C}$, the cascading control enables a quicker rise of HVDC voltage towards the limitation as shown in Fig.10 (d). It should be noted that HVDC capacitors have limited capacities and therefore limited ability for inertia support once HVDC voltage reaches the limitation. This explains the much unsmoothed profile of GSVSC output power by the cascading control observed in Fig 10 (e).

Since the cascading control only activates wind farm inertia support when HVDC voltage reaches its limitation, the duration when offshore $\mathrm{AC}$ grid frequency deviates from its nominal operation point during the disturbance is much shorter than that with the simultaneous control as seen in Fig.10 (f). This also results in a faster recovery of wind farm power output after the disturbance by the cascading control as shown in Fig. 10 (g). It is clearly seen from Fig.10 (i) and (h), the cascading control also results in smaller deviations from the optimal rotor speed, i.e. the maximum power tracking point in this case study. Consequently, the cascading control observes a less loss of wind energy harvest (S2 $\approx 0.0011)$ than that with the simultaneous control $(\mathrm{S} 1 \approx 0.0067)$. Therefore, in the Cases B and $\mathrm{C}$, it can be concluded that to achieve the same frequency deviation during the disturbance, the cascading control strategy can actually harvest more wind power than the simultaneous one. However, different from sudden load increase event in the Case A and B, the constant rotor speed deviation after disturbances is slightly higher than the optimal rotor speed determined by the MPPT algorithm as shown in Fig.10 (i) with Strategy I. As a result, amount of wind energy converts to DFIG rotor kinetic energy, leading to the energy reduction of wind farm with simultaneous control $(\mathrm{E} 1 \approx 0.0192)$ higher than S1. In contrast, the loss of captured wind energy S2 is nearly the same as E2 with cascading control since DFIG rotor speed returns to the optimal value determined by MPPT algorithm after disturbances.

\section{Big sudden load decrease with different control parame- ters}

Fig.11 shows a big sudden load decrease event on the onshore AC grid, where the dump load is doubled to $80 M W+20 M V A R$ and suddenly switched out at $t=5 \mathrm{~s}$. Voltage droop control parameter $K_{D C}$ of two control schemes are adopted the same as Case B. In order to achieve the similar frequency peaks during system disturbances, $K_{B}$ of two strategies are set as -1.5 and -4 respectively. HVDC voltage reaches 

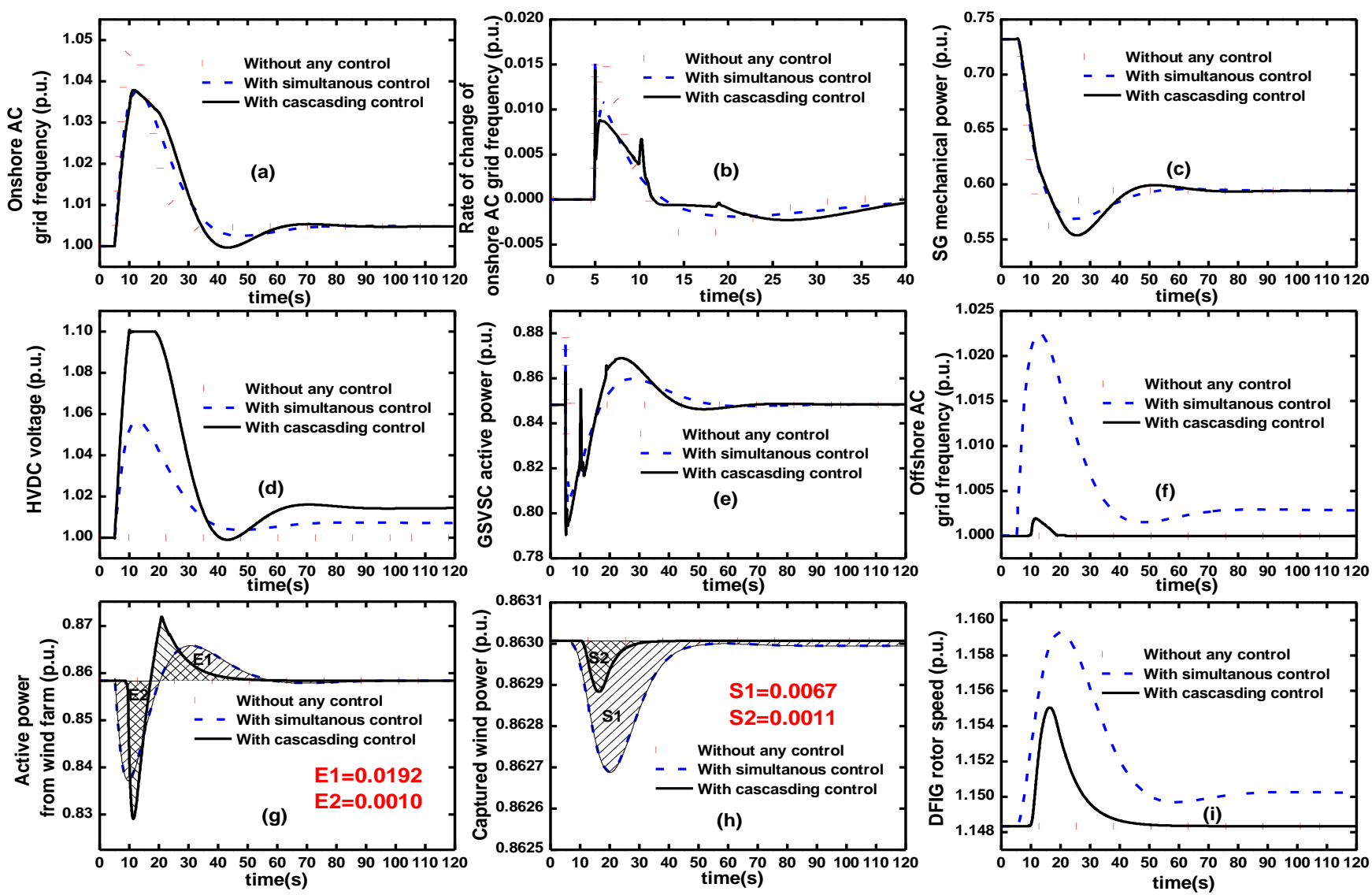

Fig.10 Simulation results for sudden load decrease in onshore AC Grid considering different control parameter
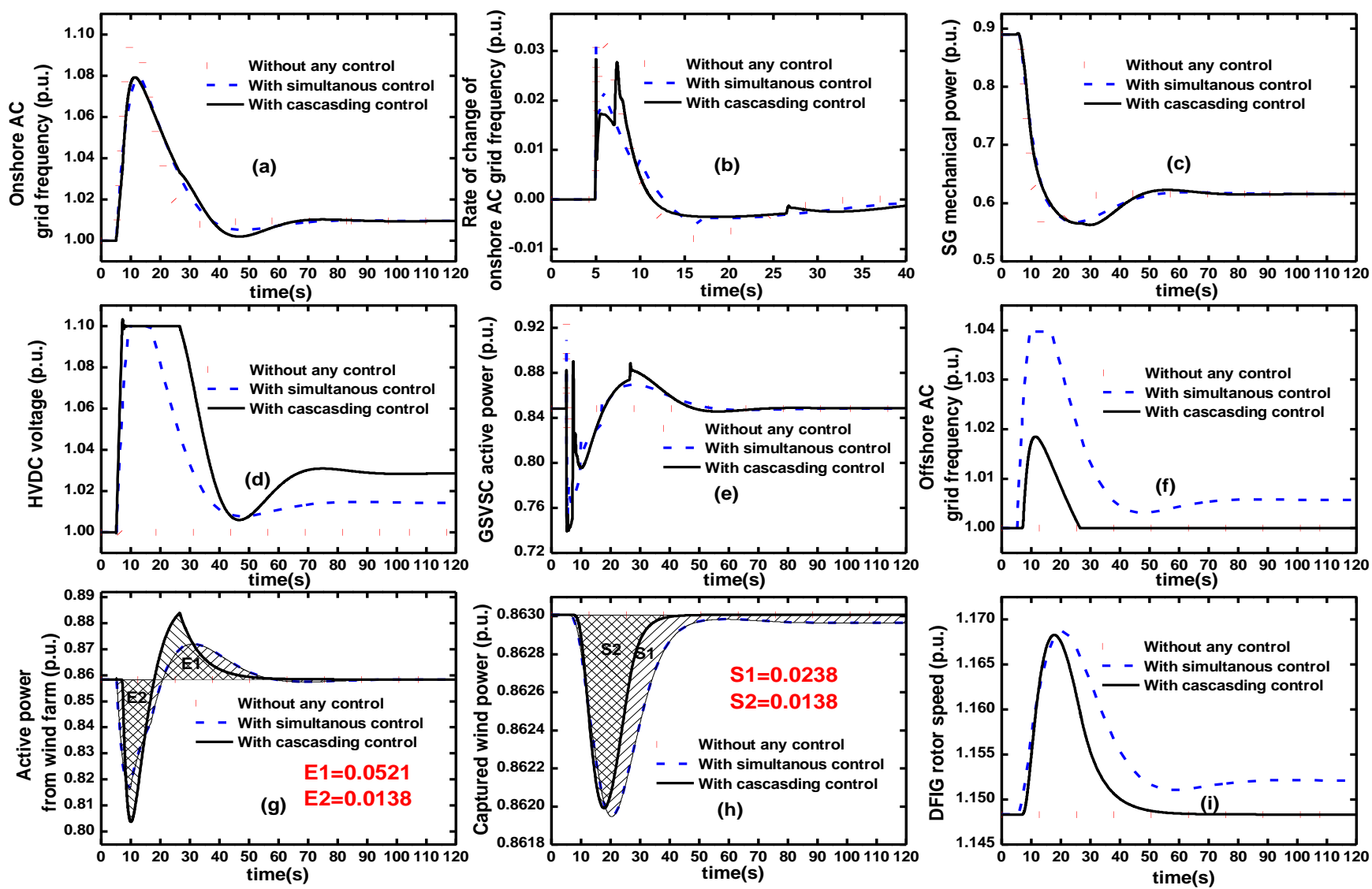

Fig.11 Simulation results for big sudden load decrease of onshore AC Grid 1 with different control parameter 
its limitation in both control strategies, as shown in Fig.11 (d). Fig.11 (g) and (i) show that under big system disturbance, the extra power provided by wind farm is nearly the same under both control strategies, indicating similar inertia support from wind farm is provided by the two control strategies. This is not unreasonable because the overall system can only obtain inertia support from wind farm when HVDC voltage beyond its limitation during big system disturbances. Although the deviations from WT MPPT under both control strategies are nearly the same, the system recovers faster with the cascading control than the simultaneous one, resulting in the loss of captured wind energy with cascading control ( $\mathrm{S} 2 \approx 0.0138$ ) less than with simultaneous control $(\mathrm{S} 1 \approx 0.0238)$, as shown in Fig.11 (h). Therefore, it again proves that the cascading control can realize wind energy harvesting as well as stabilizing system frequency. Similar to the Case C, due to the constant DFIG rotor speed deviation from the optimal value determined by MPPT algorithm after system disturbances, the energy reduction of wind farm with simultaneous control $(\mathrm{E} 1 \approx 0.0521)$ is slightly higher than the loss of captured wind energy marked as S1.

\section{E. Random load variation}

Fig.12 describes the impacts of random variations of the dump load, of which the mean value is $60 \mathrm{MW}$ and the standard deviation is $15 \mathrm{MW}$ as shown in Fig.12 (a). In order to compare two control strategies, the control parameters including e.g. $K_{B}$ adopted in this case are set the same as Case B. Fig.12 (b) shows that, both control strategies can successfully mitigate frequency variations to a similar extent compared to the case without any additional control. However, the cascading control enables a wider variations of HVDC voltage compared to that with the simultaneous control, since $K_{D C}$ with the cascading control adopts a larger $K_{D C}=3$, while the simultaneous control adopts a smaller $K_{D C}=1.5$. It is intended that HVDC capacitors are prioritized to provide inertia support by the cascading control, while the simultaneous control equally activates supports from both HVDC capacitors and wind farm. Therefore, less WT kinetic energy is utilized by the cascading control than that with the simultaneous control. It is noted form Fig.12 (e) that, compared to the case without any control, the losses of wind captured energy are 0.001 and 0.008 for the cascading control and the simultaneous control respectively. In conclusion, more wind energy can be saved when utilizing the cascading control than the simultaneous control under the random load variation scenario. It is clearly from Fig. 12 (f) that DFIG rotor speed constantly deviates from its optimal value with simultaneous control once frequency excursion occurs, which again proves Strategy I is not an energy saving strategy. Furthermore, due to the rotor speed at $t=200 \mathrm{~s}$ slightly lower than the optimal speed determined by the MPPT algorithm, amount of DFIG kinetic energy is exerted to the onshore AC grid, which results in the reduction of wind farm with Strategy I a negative value $(\mathrm{E} 1 \approx-0.0152)$. However, for a longer simulation time span, Strategy II can be more energy efficient than Strategy I while providing similar system frequency support.

\section{$F$. Influence of communication time delay to the cascading control}

Fig.13 describes the same sudden load increase event as Case B, where the influence of the time delay is induced by the communication between two converters of HVDC transmission in the cascading control. The time delay value is largely influenced by the distance of HVDC connection, sampling time of measurement units, and the response time of HVDC controller, etc. in the real applications, the communication time delay may be lower than 1 second and the worst scenario is considered in this paper.Fig.13 (a) shows that the frequency
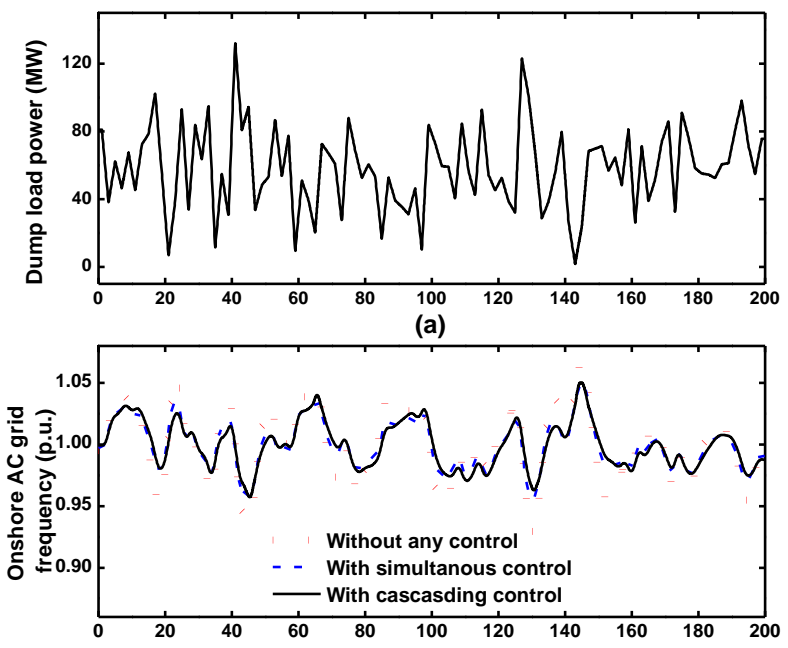

(b)

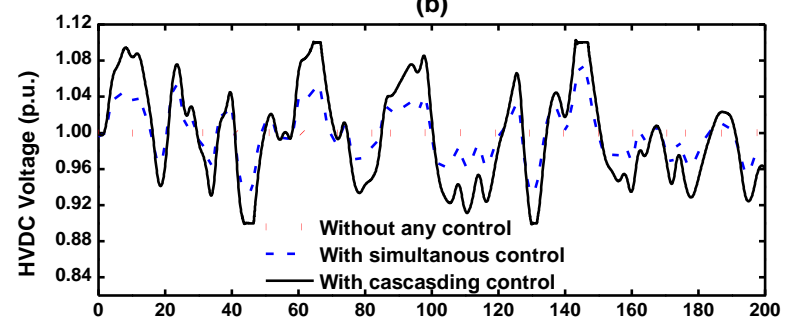

(c)

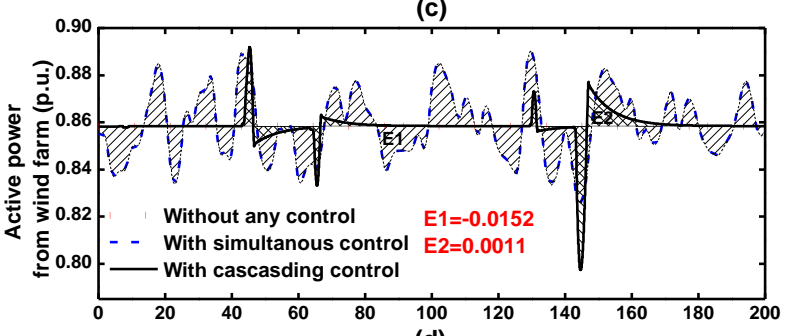

(d)

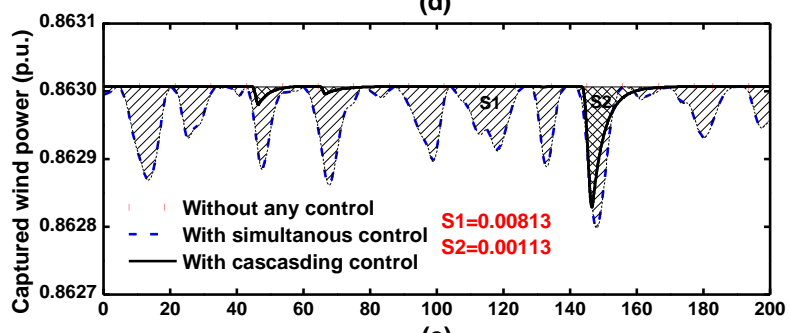

(e)

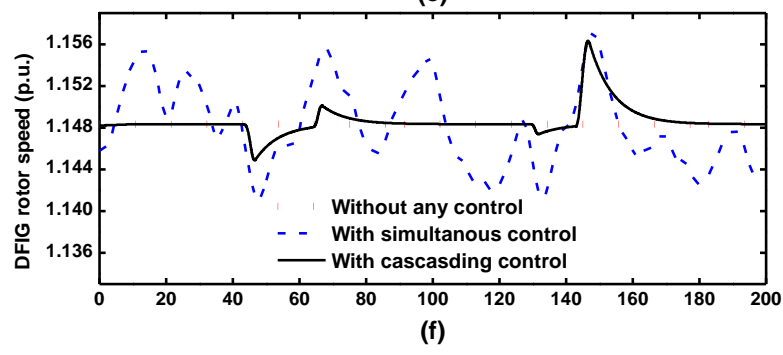

time (s)

Fig.12 Simulation results for random load variation 

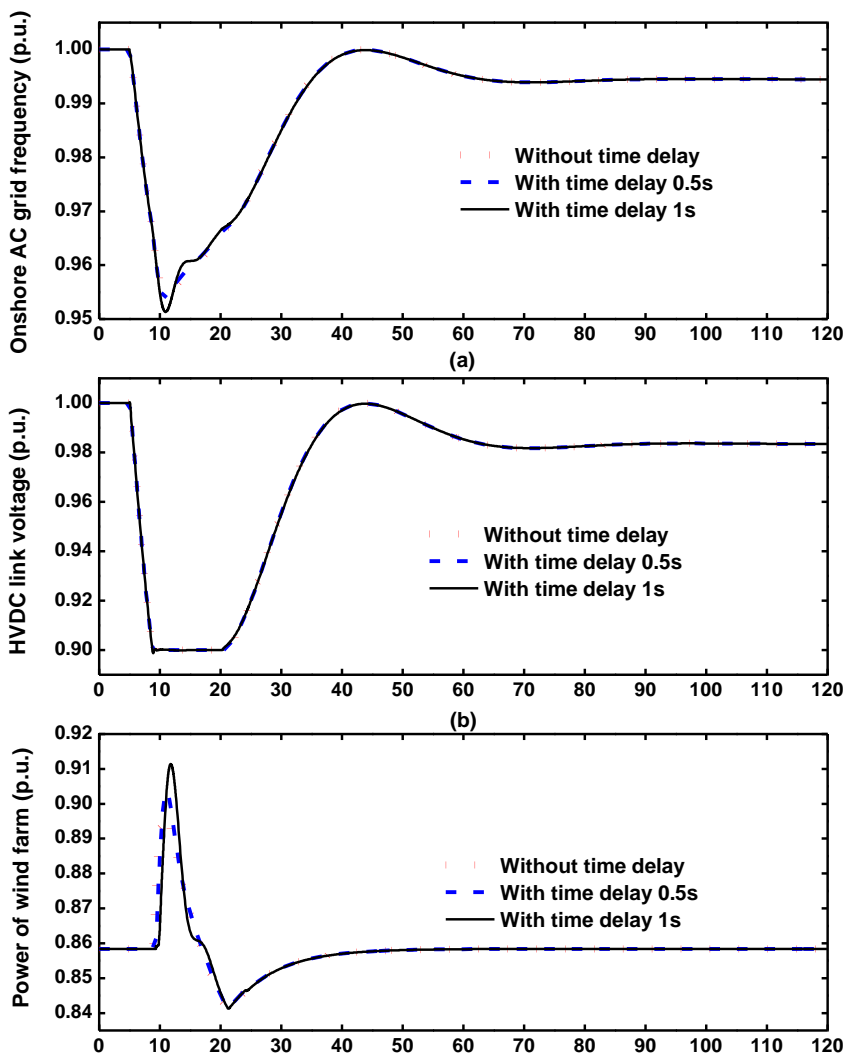

(c)

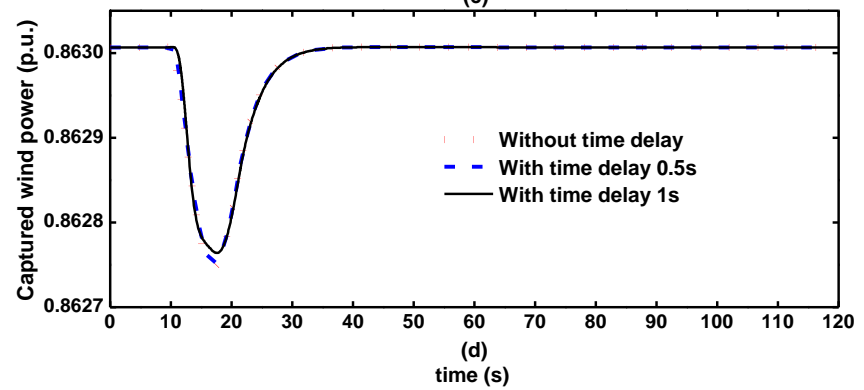

Fig.13 Influence of communication time delay on cascading control

profile of the main grid deteriorates when considering the time delay. The HVDC voltage presents similar profiles for the cases with or without time delay as shown in Fig.13 (b), since the time delay does not impact the control of GSVSC at all. It is clearly seen that the wind farm inertia control delays taking effect due to the communication time needed from the onshore grid to the offshore one. In terms of the energy captured by WT, there is no obvious difference when considering time delay as shown in Fig.13 (d).In sum; the time delay induced by the communication between two converters appears to have limited impacts on the overall performance of the proposed cascading control and the stability of the HVDC system.

\section{G. Influence of HVDC capacitor values on the performance of proposed coordinated control}

The selection of high HVDC capacitance [10] in this paper is based on the better illustration of the performance differences of two control strategies even though high capacitance may have an impaired influence on control and fault protection of HVDC system. Actually, for the overall system that the
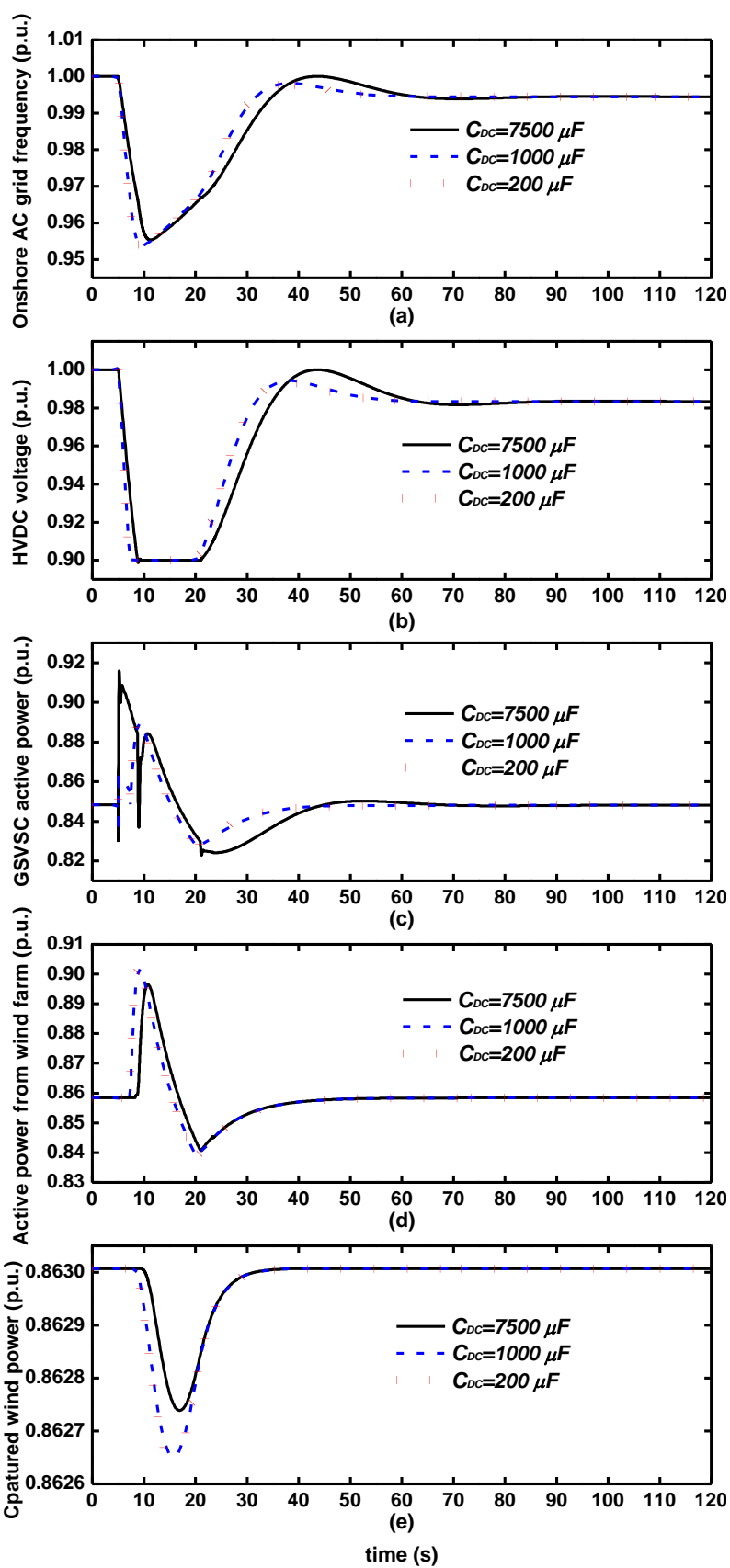

Fig. 14 Comparison of different HVDC capacitors for sudden load increase with cascading control

offshore wind farm is integrated through HVDC transmission, the inertia provided by HVDC capacitance is very limited and comparably small, while WT inertia will be the main contribution to the frequency support for the connected AC system. In the following, the impact of HVDC capacitors value on the performance of the proposed cascading control is studied.

Fig.14 shows the comparison of different HVDC capacitors values for the same sudden load increase with cascading control strategy as Case B. As shown in Fig.14 (a), the frequency nadirs of onshore AC grid with different HVDC capacitance approximately are the same. This is not unreasonable since the inertia support from WT possesses a large portion of overall system inertia support even though the inertia support from 
HVDC capacitors decreases dramatically with the decrease of HVDC capacitance. System with small HVDC capacitance release energy faster and HVDC voltage reaches its limitation faster than that with high HVDC capacitance, as shown in Fig. 14 (b). This phenomenon is more obvious as shown in Fig. 14 (c), and the active power released by HVDC capacitor is smaller with small HVDC capacitance. With larger capacitors, a transient active power oscillation will appear in the inception of the event as shown in Fig. 14 (c). Fig. 14 (d) and (e) point out that, WT exerts more active power for system inertia support with small HVDC capacitance and accordingly, has a more loss of wind energy harvest than that with high HVDC capacitance. It is concluded that with cascading control, the HVDC capacitors value has little effect on the overall system inertia support.

\section{CONCLUSIONS}

This paper focuses on coordinated control strategies for offshore wind farms integrated to main grids via HVDC transmission aiming at providing fast system inertia support. Our previously proposed simultaneous control is a communicationfree (without the need of any communication links established between onshore and offshore grids) scheme to utilize the HVDC capacitor energy and WT inertia simultaneously for onshore AC grid support. In contrast, the newly proposed cascading control in this paper can orderly exert HVDC capacitor energy and then WT inertia with the aid of communication between the onshore and offshore grids. Detailed design and case study of the two control strategies have been conducted. It is shown from the test system that given the same disturbance event, both strategies can demonstrate similar performance in stabilizing system frequency if the control parameters are set properly in advance. In addition, the cascading control distinguishes itself by enabling better wind energy harvest during disturbances. Further, the impact of time delay induced by implementing communication between two converters of HVDC might have limited impacts on the control performance and overall system stability by the cascading control. It is believed that the two novel strategies can largely facilitate HVDC based wind farms development in the future.

APPENDIX

TABLE A1 PARAMETERS OF THE HVDC LINK

\begin{tabular}{llc}
\hline \hline Symbol & \multicolumn{1}{c}{ Item } & Value \\
\hline$S_{B}$ & Rated VSC power & $300 \mathrm{MVA}$ \\
$U_{V S C}$ & Rated VSC AC rms Voltage & $110 \mathrm{kV}$ \\
$V_{D C n}$ & Nominal DC voltage & $200 \mathrm{kV}$ \\
$C_{D C}$ & DC capacitor & $7500 \mu \mathrm{F}$ \\
$L_{T}$ & Inductance of transformer & $0.15 \mathrm{p} . \mathrm{u}$. \\
$R_{T}$ & Resistance of transformer & $0.005 \mathrm{p} . \mathrm{u}$. \\
$R_{l}$ & Resistance of cables & $0.025 \Omega / \mathrm{km}$ \\
$H_{l}$ & Inductance of cables & $0.2 \mathrm{mH} / \mathrm{km}$ \\
$f_{W F O}$ & WFVSC1,2 initial set point & $1 \mathrm{p.u.} .(50 \mathrm{~Hz})$ \\
$K_{A}$ & WFVSC frequency droop control & 0.4 \\
\hline
\end{tabular}

TABLE A2 PARAMETERS OF THE SG

\begin{tabular}{llc}
\hline \hline \multicolumn{1}{c}{ Symbol } & \multicolumn{1}{c}{ Item } & Value \\
\hline$S_{g}$ & Rated MVA & $300 \mathrm{MVA}$ \\
$U_{g}$ & Terminal Voltage & $13.8 \mathrm{kV}$ \\
$H_{g}$ & Inertia Time constant & $4 \mathrm{~s}$ \\
$x_{d,}, x_{d}, x_{d}$, & d-axis synchronous reactance & $2.642,0.377,0.21$ \\
$x_{q}, x_{q},{ }^{\prime}, x_{l}$ & q-axis synchronous reactance & $2.346,0.18,0.18$
\end{tabular}

\begin{tabular}{llc}
$T_{d}{ }^{\prime}, T_{d}{ }^{\prime}, T_{q}{ }^{\prime}$, & SG Time constant & $0.635,0.015,0.015$ \\
\hline$R_{P}$ & Turbine permanent droop & 0.04 \\
$T_{r}$ & Governor time constant & $8.408 \mathrm{~s}$ \\
$T_{\text {servo }}$ & Servo-motor time constant & $0.5 \mathrm{~s}$ \\
\hline$K_{\text {gain }}$ & Exciter regulator gain & 400 \\
$T_{e}$ & Exciter time constant & $0.01 \mathrm{~s}$ \\
\hline
\end{tabular}

The parameters of studied DFIG WT are as follows:

Wind tubine: cut in wind speed: $4 \mathrm{~m} / \mathrm{s}$; lower limit of the wind speed: $7 \mathrm{~m} / \mathrm{s}$; rated wind speed: $14 \mathrm{~m} / \mathrm{s}$; inertia constant: $H_{t}=3.5 \mathrm{~s}$; damping coefficient: $D_{s h}=0.01$ p.u.; shaft stiffness coefficient: $K_{s h}=0.5$ p.u.; time constant of the pitch serve: $T_{\beta}=0.25 \mathrm{~s}$.

Single-DFIG: rated power: $2 \mathrm{MW}$; rated voltage: $690 \mathrm{~V}$; rated rotor speed: 1.23 p.u.; inertia constant: $H_{g}=1.55 \mathrm{~s}$; friction coefficient: $B=0.01$ p.u.; stator resistance: $R_{s}=0.00706$ p.u.; rotor resistance: $R_{r}=0.0005$ p.u.; stator leakage inductance: $L_{l s}=0.171$ p.u.; rotor leakage inductance: $L_{l r}=0.156$ p.u.; mutual inductance: $L_{m}=3.5$ p.u.

Converters: resistance of grid side inductor: $R_{L}=0.003$ p.u.; inductance of grid side inductor: $L=0.3$ p.u.; DC-link capacitor: $C_{d c_{-} d f i g}=0.06 \mathrm{~F}$.

\section{REFERENCES}

[1] J. Han, and A. Papavasiliou, "The Impacts of Transmission Topology Control on the European Electricity Network", IEEE Transactions on Power Systems, 2015, PP, (99), pp. 1-12.

[2] M. Kayikci and J. V. Milanovic, "Dynamic Contribution of DFIG-Based Wind Plants to System Frequency Disturbances," Ieee Transactions on Power Systems, vol. 24, pp. 859-867, May 2009.

[3] M.F.M. Arani, and E.F. El-Saadany, "Implementing Virtual Inertia in DFIG-Based Wind Power Generation", IEEE Transactions on Power Systems, 2013, 28, (2), pp. 1373-1384.

[4] M.F.M. Arani, and Y.A.R.I. Mohamed, "Analysis and Impacts of Implementing Droop Control in DFIG-Based Wind Turbines on Microgrid/Weak-Grid Stability", IEEE Transactions on Power Systems, 2015, 30, (1), pp. 385-396.

[5] Y. Wang, J. Meng, X. Zhang, and L. Xu, "Control of PMSG-Based Wind Turbines for System Inertial Response and Power Oscillation Damping", IEEE Transactions on Sustainable Energy, 2015, 6, (2), pp. 565-574.

[6] N. Flourentzou, V. G. Agelidis, and G. D. Demetriades, "VSC-Based HVDC Power Transmission Systems: An Overview," IEEE Transactions on Power Electronics, vol. 24, pp. 592-602, Mar-Apr 2009.

[7] L. Xu, L. Z. Yao, and C. Sasse, "Grid integration of large DFIG-based wind farms using VSC transmission," IEEE Transactions on Power Systems, vol. 22, pp. 976-984, Aug 2007.

[8] L. Wang and M. S. N. Thi, "Stability Enhancement of a PMSG-Based Offshore Wind Farm Fed to a Multi-Machine System Through an LCCHVDC Link," Ieee Transactions on Power Systems, vol. 28, pp. 33273334, Aug 2013.

[9] R. Blasco-Gimenez, S. Ano-Villalba, J. Rodriguez-D'Derlee, F. Morant, and S. Bernal-Perez, "Distributed Voltage and Frequency Control of Offshore Wind Farms Connected With a Diode-Based HVdc Link," IEEE Transactions on Power Electronics, vol. 25, pp. 3086-3105, Dec 2010.

[10] J. B. Zhu, C. D. Booth, G. P. Adam, A. J. Roscoe, and C. G. Bright, "Inertia Emulation Control Strategy for VSC-HVDC Transmission Systems," IEEE Transactions on Power Systems, vol. 28, pp. 1277-1287, May 2013.

[11] Y. Phulpin, "Communication-Free Inertia and Frequency Control for Wind Generators Connected by an HVDC-Link," IEEE Transactions on Power Systems, vol. 27, pp. 1136-1137, May 2012.

[12] Y. Pipelzadeh, B. Chaudhuri, and C. Green, "Inertial Response from Remote Offshore Wind Farms Connected Through VSC-HVDC Links: A Communication-less Scheme," 2012 IEEE Power and Energy Society General Meeting, 2012.

[13] Y. J. Li, Z. R. Zhang, Y. Yang, Y. Y. Li, H. R. Chen, and Z. Xu, "Coordinated control of wind farm and VSC-HVDC system using capacitor energy and kinetic energy to improve inertia level of power systems," International Journal of Electrical Power \& Energy Systems, vol. 59, pp. 79-92, Jul 2014. 
[14] A. Junyent Ferre, Y. Pipelzadeh, and T. Green, "Blending HVDC-Link Energy Storage and Offshore Wind Turbine Inertia for Fast Frequency Response," IEEE Transactions on Sustainable Energy, vol. PP, pp. 1-8, 2015.

[15] H. Liu and Z. Chen, "Contribution of VSC-HVDC to Frequency Regulation of Power Systems With Offshore Wind Generation," Energy Conversion, IEEE Transactions on, vol. PP, pp. 1-9, 2015.

[16] C. Feltes, H. Wrede, F. W. Koch, and I. Erlich, "Enhanced Fault RideThrough Method for Wind Farms Connected to the Grid Through VSCBased HVDC Transmission," IEEE Transactions on Power Systems, vol. 24, pp. 1537-1546, Aug 2009.

[17] B. Silva, C. L. Moreira, H. Leite, and J. A. P. Lopes, "Control Strategies for AC Fault Ride Through in Multiterminal HVDC Grids," IEEE Transactions on Power Delivery, vol. 29, pp. 395-405, Feb 2014.

[18] B. Silva, C. L. Moreira, L. Seca, Y. Phulpin, and J. A. P. Lopes, "Provision of Inertial and Primary Frequency Control Services Using Offshore Multiterminal HVDC Networks," IEEE Transactions on Sustainable Energy, vol. 3, pp. 800-808, Oct 2012.

[19] R. Pena, J. C. Clare, and G. M. Asher, "A doubly fed induction generator using back-to-back PWM converters supplying an isolated load from a variable speed wind turbine," IEE Proceedings-Electric Power Applications, vol. 143, pp. 380-387, Sep 1996.

[20] J. B. Ekanayake, L. Holdsworth, X. G. Wu, and N. Jenkins, "Dynamic modeling of doubly fed induction generator wind turbines," IEEE Transactions on Power Systems, vol. 18, pp. 803-809, May 2003.

[21] A.D. Hansen, F. Iov, P. Sørensen, N. Cutululis, C. Jauch, and F. Blaabjerg, "Dynamic wind turbine models in power system simulation tool", DIgSILENT Project Report Ris $\varnothing-R-1400($ ed.2)(EN).

[22] P. Anderson and A. A. Fouad, Power System Control and Stability. Ames, IA: Iowa State Univ. Press, 1977.

[23] N. Flourentzou, V. G. Agelidis, and G. D. Demetriades, "VSC-Based HVDC Power Transmission Systems: An Overview," IEEE Transactions on Power Electronics, vol. 24, pp. 592-602, Mar-Apr 2009.

[24] J. F. M. Padron and A. E. F. Lorenzo, "Calculating Steady-State Operating Conditions for Doubly-Fed Induction Generator Wind Turbines," IEEE Transactions on Power Systems, vol. 25, pp. 922-928, May 2010.

[25] M.N. Kabir, Y. Mishra, G. Ledwich, Z. Xu, R.C. Bansal, "Improving voltage profile of residential distribution systems using rooftop PVs and Battery Energy Storage systems”, Applied Energy 134 (2014) 290 - 300.

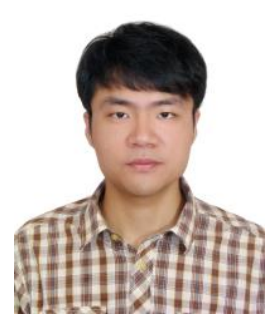

Yujun Li (S'15) received his B.Sc and M.Sc degrees from Xi'an Jiaotong University, China, in 2011, and Zhejiang University, China, in 2014 in Electrical Engineering, respectively. He is currently pursuing the Ph.D degree in Hong Kong Polytechnic University. His main fields of interest include grid integration of renewable energy and HVDC modeling.

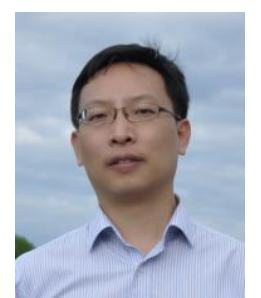

Zhao Xu (M'06-SM'13) received the Ph.D. degree in electrical engineering from The University of Queensland, Brisbane, Australia, in 2006.From 2006 to 2009, he was an Assistant and later Associate Professor with the Centre for Electric Technology, Technical University of Denmark, Lyngby, Denmark. Since 2010, he has been with Hong Kong Polytechnic University. His research interests include demand side, grid integration of wind power, electricity market planning and management, and AI applications. He is an Editor of the Electric Power Components and Systems Journal, IEEE Transaction on Smart Grid, and IEEE Power Engineering Letter.

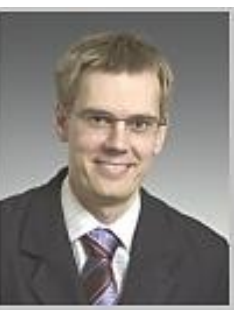

Jacob Østergaard (M'95,-SM'09) is Professor and Head of the Centre for Electric Power and Energy, Department of Electrical Engineering, Technical University of Denmark, Lyngby, Denmark. His research interests include integration of renewable energy, control architecture for future power system, and demand side. Prof. Østergaard is serving in several professional organizations including the EU SmartGrids advisory council.

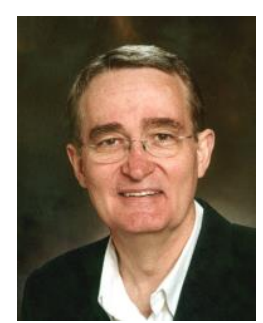

David J. Hill (S'72-M'76-SM'91-F'93-LF'14) received the $\mathrm{Ph} . \mathrm{D}$. degree in electrical engineering from the University of Newcastle, Australia, in 1976. He was the Chair of Electrical Engineering with the Department of Electrical and Electronic Engineering, University of Hong Kong. He is also a Part-Time His general research interests are in control systems, complex networks, power systems, and stability analysis. His work is now mainly on control and planning of future energy networks, and basic stability and control questions for dynamic networks.

Prof. Hill is a Fellow of the Society for Industrial and Applied Mathematics, USA; the Australian Academy of Science; and the Australian Academy of Technological Sciences and Engineering. He is also a Foreign Member of the Royal Swedish Academy of Engineering Sciences. 